\title{
Erasing Fear Memories with Extinction Training
}

\author{
Gregory J. Quirk, ${ }^{1}$ Denis Paré, ${ }^{2}$ Rick Richardson, ${ }^{3}$ Cyril Herry, ${ }^{4}$ Marie H. Monfils, ${ }^{5}$ Daniela Schiller, ${ }^{6}$ \\ and Aleksandra Vicentic ${ }^{7}$ \\ ${ }^{1}$ Departments of Psychiatry and Anatomy and Neurobiology, University of Puerto Rico School of Medicine, San Juan 00936-5067, Puerto Rico, ${ }^{2}$ Center for \\ Molecular and Behavioral Neuroscience, Rutgers, State University of New Jersey, Newark, New Jersey 07102, ${ }^{3}$ School of Psychology, University of New \\ South Wales, Kensington, Sydney, New South Wales 2052, Australia, ${ }^{4}$ INSERM U862, Neurocentre Magendie, 33077 Bordeaux, France, ${ }^{5}$ Department of \\ Psychology, University of Texas, Austin, Texas 78712, ${ }^{6}$ Center for Neural Science, New York University, New York, New York 10003, and ${ }^{7}$ National Institute \\ of Mental Health, Rockville, Maryland 20852
}

Decades of behavioral studies have confirmed that extinction does not erase classically conditioned fear memories. For this reason, research efforts have focused on the mechanisms underlying the development of extinction-induced inhibition within fear circuits. However, recent studies in rodents have uncovered mechanisms that stabilize and destabilize fear memories, opening the possibility that extinction might be used to erase fear memories. This symposium focuses on several of these new developments, which involve the timing of extinction training. Extinction-induced erasure of fear occurs in very young rats, but is lost with the development of perineuronal nets in the amygdala that render fear memories impervious to extinction. Moreover, extinction administered during the reconsolidation phase, when fear memory is destabilized, updates the fear association as safe, thereby preventing the return of fear, in both rats and humans. The use of modified extinction protocols to eliminate fear memories complements existing pharmacological strategies for strengthening extinction.

\section{Introduction}

The last decade has witnessed a resurgence of interest in the neural mechanisms of Pavlovian extinction, especially related to fear conditioning. In extinction, a tone conditioned stimulus (CS) that predicts a shock unconditioned stimulus (US) is repeatedly presented in the absence of the US, causing conditioned fear responses to diminish. With sufficient extinction, subjects (rats or people) respond to the CS as if they had never been conditioned. However, decades of psychological studies have shown that extinguished fear responses return with the passage of time, when the CS is presented in a different context, or following an aversive event (Pavlov, 1927; Rescorla and Heth, 1975; Bouton and Bolles, 1979). The return of fear after extinction is behavioral evidence that extinction does not erase fear memories, but instead generates an inhibitory memory capable of temporarily suppressing the expression of fear associations. Indeed, an increasing number of studies are characterizing the neural mechanisms of this inhibition, focusing on the amygdala, prefrontal cortex, and hippocampus (for review, see Myers and Davis, 2007; Quirk and Mueller, 2008; Pape and Paré, 2010; Radulovic and Tronson, 2010; Herry et al., 2010). From a clinical perspective, the return of fear after extinction is thought to contribute to relapse following exposure-based therapies for anxiety disorders (Bruce et al., 2005). Thus, there is a need for new behavioral methods capable of modifying the original fear memory.

\footnotetext{
Received Aug. 15, 2010; revised Sept. 10, 2010; accepted Sept. 13, 2010

Correspondence should be addressed to Dr. Gregory J. Quirk, Department of Psychiatry, University of Puerto Rico, School of Medicine, PO Box 365067, San Juan 00936-5067, Puerto Rico. E-mail: gjquirk@yahoo.com.

DOI:10.1523/JNEUROSCI.4268-10.2010

Copyright $\odot 2010$ the authors $\quad$ 0270-6474/10/3014993-05\$15.00/0
}

In recent years, the idea that extinction does not involve erasure has been challenged. Increasing evidence indicates that extinction reverses some of the conditioning-induced processes within the amygdala. For example, extinction activates phosphatases that dephosphorylate CREB and other targets of conditioning (Lin et al., 2003b). Consistent with a reversal of conditioninginduced changes, extinction training causes depotentiation of CS inputs to the amygdala and induces AMPA receptor endocytosis (Lin et al., 2003a; Kim et al., 2007). These findings suggest that extinction may erase some aspects of fear memory within the amygdala, even though fear can still return at the behavioral level. Moreover, in the past year, we have learned that simple modifications of the extinction protocol allow extinction to reduce fear in such a way that it does not return, consistent with a brain-wide modification of the original fear memory. This symposium describes these recent approaches in rodent and humans, which involve alterations in the timing of extinction trials, both within a session and across the lifespan of the animal. In addition to revealing new ways to regulate fear, these findings could dramatically improve the effectiveness of extinction-based methods to treat anxiety.

\section{The ontogeny of extinction: from erasure to inhibition}

It is becoming clear that fundamentally different circuits mediate extinction of learned fear at different stages of development. In rats, extinction at the postweaning stage [e.g., $24 \mathrm{~d}$ of age (P24)] has the same characteristics as documented in adult rats, namely, it is dependent on the medial prefrontal cortex (mPFC) and requires NMDA receptor activation (Kim and Richardson, 2010b). Fear extinction in the preweaning stage of rats [e.g., a rat $17 \mathrm{~d}$ of age (P17)], however, is quite different. For example, mPFC plays no role in fear extinction at that age. Using auditory fear conditioning to a white noise CS, Kim et al. (2009) showed that tem- 
porary inactivation of the $\mathrm{mPFC}$ during extinction training at P24 markedly impaired retention of extinction, whereas temporary inactivation of the $\mathrm{mPFC}$ at $\mathrm{P} 17$ had no effect. Furthermore, P24 rats exhibited increased neuronal activity in the MPFC following extinction, but P17 rats did not. Other studies from this same group have shown that neither NMDA receptors nor GABA receptors are necessary for extinction of learned fear in the P17 rat (for review, see Kim and Richardson, 2010b). Thus, the well established NMDA-dependent plasticity in inhibitory circuits within the prefrontal cortex and amygdala does not appear to subserve extinction in very young rats.

Moreover, it appears that preweaning extinction erases fear memories, whereas postweaning extinction does not. Rats extinguished at P17 do not exhibit a return of fear when tested in a context different from that in which extinction training occurred (i.e., renewal) or following a pretest stressor (i.e., reinstatement). In contrast, rats extinguished at $24 \mathrm{~d}$ of age exhibit a return of fear in both of these situations (Kim and Richardson, 2010b). This reduced susceptibility to relapse appears to be determined by the rat's age at the time of extinction training rather than their age at the time of conditioning (Yap and Richardson, 2007). This same pattern of results is observed in regard to the involvement of the NMDA receptor in extinction of learned fear. That is, the NMDA receptor antagonist MK-801 impairs extinction retention if extinction training occurs on P24 but not if it occurs on P17, even when the age at training and testing is held constant across groups (Kim and Richardson, 2010a). The adaptive function of the resistance of postweaning fear memories to extinction remains speculative. One possibility is that dangers likely to be encountered postweaning, when rats are exploring their environment and searching for food, are more important to retain from a survival standpoint.

\section{The role of perineuronal nets in the ontogeny of extinction}

What mechanisms might explain the developmental regulation of extinction? Clues may be gleaned from studies of sensorimotor systems, where the development of inhibitory circuits marks the opening and closing of critical periods for structural and functional plasticity (Berardi et al., 1999; Hensch, 2005). During the early critical period for plasticity in the visual cortex, monocular deprivation shifts ocular dominance to the nondeprived eye, a phenomenon not observed when light deprivation is performed after the critical period. A similar critical period exists for postnatal maturation of perineuronal nets (PNNs), which are a highly organized form of chondroitin sulfate proteoglycan-containing extracellular matrices that surround inhibitory interneurons (Berardi et al., 2003; Hensch, 2005). In the visual cortex, the development of PNNs coincides with the end of the critical period for ocular dominance plasticity (Berardi et al., 2003; Hensch, 2005). A similar phenomenon has recently been described for experience-dependent plasticity in the murine barrel cortex, as well as for song learning plasticity in the zebra finch sensorimotor system (Balmer et al., 2009; Nowicka et al., 2009). Together, these data suggest that the absence of PNNs early in life might constitute a conserved mechanism allowing for developmental plasticity.

The amygdala also contains PNNs, and it was recently suggested that they serve the same role as in sensorimotor systems in the developmental regulation of fear extinction (Gogolla et al., 2009). Maturation of PNNs in the mouse amygdala coincides with the end of the developmental period during which extinction induces erasure of fear memories, suggesting that PNNs prevent extinction from erasing fear. Consistent with this, pharmacological degradation of PNNs in the amygdala of adult mice enabled extinction to erase conditioned fear without interfering with fear consolidation, reconsolidation, or expression. This effect was specific for fear memories acquired in the absence of PNNs; eliminating PNNs in adult rats that acquired fear with PNNs intact had no effect on extinction. This suggests that acquiring fear memories in the presence of PNNs protects conditioned fear memories from extinction-induced erasure, allowing extinction memories to coexist with previously acquired fear memories (Gogolla et al., 2009).

Although the underlying mechanisms are still unclear, one possible explanation for the protective action of PNNs on fear memories is changes in local GABAergic inhibition. Indeed, PNNs form primarily around parvalbumin-positive GABAergic interneurons, and GABAergic inhibition regulates various forms of plasticity in the amygdala (Bissière et al., 2003; Shaban et al., 2006). Thus, formation of PNNs may alter the function of local inhibitory circuits to promote the formation of an erasureresistant memory trace during fear conditioning. Because recovery of conditioned fear responses is believed to contribute to the relapse of pathological fear in anxiety disorders (Bruce et al., 2005), these findings point to novel strategies for preventing the development of extinction-resistant pathological fear and anxiety.

\section{Extinguishing fear during windows of fear consolidation or reconsolidation}

Extinction in young animals appears to erase fear memories, but are there circumstances in which this occurs in adults? Recent findings suggest so: extinction may reverse or update prior learning if it occurs within a discrete time window following reactivation (or retrieval), when fear memories are unstable, malleable, or otherwise susceptible to disruption. During initial encoding of events, memories are labile, but subsequently consolidate into long-term storage through protein synthesis-dependent mechanisms. Upon retrieval, a previously consolidated memory trace becomes labile anew, and must undergo a second round of protein synthesis to be restored (a phenomenon known as reconsolidation) (Misanin et al., 1968; Nader and Einarsson, 2010). Thus, in adulthood, there are two discrete periods in which memories may be updated or erased: during consolidation and reconsolidation.

In the case of consolidation, updating of the fear memory can take place when extinction training is given shortly after acquisition-a procedure called immediate extinction. First discovered by Myers et al. (2006), extinction training applied immediately after fear conditioning was shown to prevent the consolidation of the fear memory, thereby preventing the return of fear. Subsequent experiments using variations of this protocol have met with limited success (Maren and Chang, 2006; Norrholm et al., 2008; Schiller et al., 2008; Woods and Bouton, 2008), suggesting the involvement of other, as yet unknown, variables. Also, from a translational perspective, it may be difficult to initiate extinctionbased therapies within the brief post-trauma time window indicated by the rodent studies (10-60 min after conditioning).

In the case of reconsolidation, Monfils et al. (2009) offered evidence that this window may allow updating of fear memories by extinction. Using a fear conditioning paradigm in rats, these authors showed that reactivating the fear memory with a single isolated CS shortly before extinction training resulted in an apparent reevaluation of the CS as nonthreatening. Indeed, rats extinguished shortly after reactivation did not show spontaneous recovery, renewal, or reinstatement of fear (Monfils et al., 2009). Thus, simply manipulating the timing of the first nonreinforced 

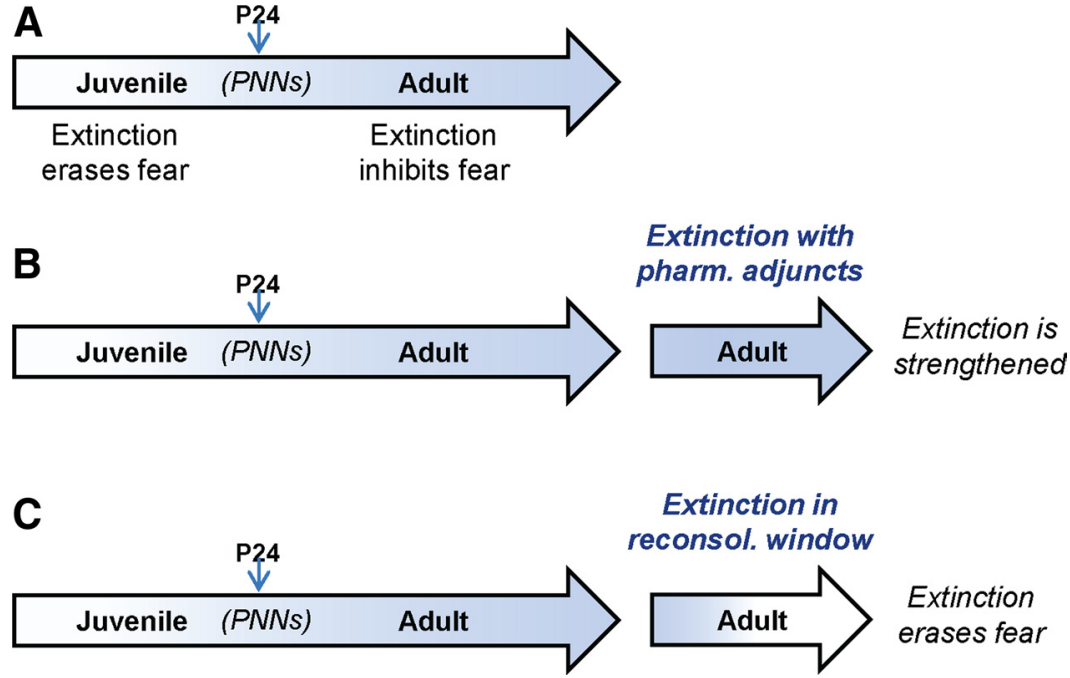

Figure 1. Schemas showing how different extinction procedures might interact with fear memory. $\boldsymbol{A}$, Under standard conditions, extinction erases fear in very young rats ( $<24 \mathrm{~d}$ of age). Above this age, extinction leaves the fear memory intact but inhibits its expression. The transition corresponds to the development of PNNs in the amygdala. $\boldsymbol{B}$, Extinction with pharmacological (pharm.) adjuncts such as D-cycloserine strengthens extinction, but still leaves fear memories intact. C, Administering extinction shortly after a reactivation of the fear memory, during its reconsolidation (reconsol.) window, erases the original fear memory, converting it to a safety memory. Blue shading represents the strength of the fear memory.

CS yielded an effect resembling unlearning, as opposed to inhibition of fear. This effect can be viewed as a reconsolidationupdating mechanism, because it occurs only when extinction training is given during the reconsolidation window (within $6 \mathrm{~h}$ after memory reactivation in rats) (Nader et al., 2000).

The modification of the original fear memory with reconsolidationbased extinction may have advantages over pharmacological approaches to facilitating extinction. Rodent studies have firmly established that the partial NMDA agonist D-cycloserine (DCS) facilitates extinction learning (Walker et al., 2002; Richardson et al., 2004; Ledgerwood et al., 2005), but the extinguished fear can still be renewed with a change of context (Woods and Bouton, 2006). Thus, it seems that the reduction of fear following reconsolidation-based extinction is due to a reversal (or updating) of the fear memory, and not because the extinction itself is rendered more efficacious. Understanding the factors that permit memory updating within consolidation and reconsolidation windows should enhance our ability to successfully target pathological memories in a clinical context.

\section{Translating rodent studies of reconsolidation and extinction to humans}

Although much evidence indicates that fear memory reconsolidation can be blocked in various species (Nader and Einarsson, 2010), it has been difficult to test this in humans. Indeed, only two studies recently demonstrated encouraging support for reconsolidation of emotional memories in posttraumatic stress disorder (PTSD) patients (Brunet et al., 2008) and in healthy volunteers that underwent fear conditioning (Kindt et al., 2009). One of the major reasons for the slow pace of human reconsolidation research is that most compounds used to block reconsolidation in animals, such as protein synthesis inhibitors (e.g., anisomycin), are toxic in humans. Moreover, different physiological measures of fear in humans (e.g., fear potentiated startle vs skin conductance response) (Soeter and Kindt, 2010) could be differently affected by pharmacological agents.
These difficulties underscore the need for nonpharmacological methods to block reconsolidation in humans. The idea that drugs might be replaced with extinction training grew out of the view of reconsolidation as an update mechanism (Dudai, 2006), in which the information available at the time of retrieval should theoretically be incorporated into the retrieved memory while it is undergoing reconsolidation. In this way, the memory would no longer exist in its original form. The notion of reconsolidation as an updating mechanism has received support from human studies targeting motor and declarative memories (Walker et al., 2003; Forcato et al., 2007; Hupbach et al., 2007). Given the encouraging results with fear memory in rodents (Monfils et al., 2009), Schiller et al. (2010) attempted to translate the combined reconsolidation/extinction technique to healthy humans undergoing fear conditioning. They were able to replicate the basic finding that extinction training performed during the reconsolidation window (10 min after reactivation) reduced fear in such a way that it did not show spontaneous recovery nor did it return following a reinstating shock. They further showed that this effect was specific to the reactivated memory, and did not occur with other (non-reactivated) fear memories. Underscoring the potential clinical significance of the finding, the reduction in fear obtained with the reconsolidation/extinction technique lasted at least one year. These results are encouraging from a clinical standpoint; however, it remains unclear whether the reconsolidation/extinction technique can alter traumatic memories in patients suffering from anxiety disorders.

\section{Improving the effectiveness of extinction-based therapies for anxiety disorders}

Recent developments in extinction and reconsolidation research have begun to blur the boundaries between basic and clinical research (Fig. 1). The growing use of DCS as a pharmacological adjunct to facilitate extinction was derived from early rodent studies (Falls et al., 1992; Walker et al., 2002), but has now shown promise in clinical studies for PTSD, obsessive-compulsive disorder, phobia, and social anxiety disorder (for review, see Ganasen et al., 2010). By strengthening extinction, pharmacological adjuncts can reduce the return of fear, as well as reduce the number of therapy sessions required to achieve a therapeutic effect. Other compounds may be useful for strengthening or accelerating extinction, as suggested by recent rodent studies. These include fibroblast growth factor, methylene blue, endocannabinoids, and yohimbine (Gonzalez-Lima and Bruchey, 2004; Morris and Bouton, 2007; Chhatwal et al., 2009; Graham and Richardson, 2010). New studies elucidating the mechanism of extinction-induced inhibition within the amygdala (Ehrlich et al., 2009; Amano et al., 2010; Pape and Paré, 2010) will likely lead to additional pharmacological targets. In fact, a recent study suggests that extinction may even be induced by purely pharmacological means (Peters et al., 2010).

The discovery that extinction in juveniles erases early fears could be exploited for treatment of childhood traumas. Indeed, extinction-based therapies have been successful with children as 
young as 7 years of age (Ollendick et al., 2009). It is now becoming clear that fear conditioning in very young rodents can lead to paradoxical approach behaviors to the CS, which are regulated by stress hormones (Moriceau et al., 2006). Together with the findings on PNNs, this suggests that the developmental switches that regulate the stability and aversiveness of fear memories might be manipulated for clinical gains. The new approaches targeting a specific time window for extinction, when fear memories are unstable, represent a critical advance in the field that should be further explored. Most needed are parametric studies to determine the optimal time window to permanently erase fear, especially in anxiety disorder patients. Future therapies could feature relatively simple modifications to the timing of exposure sessions, and/or the use of pharmacological adjuncts given after the session to facilitate consolidation of safety learning.

\section{Potential applications beyond anxiety disorders}

Deficits in extinction circuits are also apparent in neuropsychiatric conditions other than anxiety disorders (Milad and Rauch, 2007). For example, extinction appears to be deficient in drug addiction (Conklin and Tiffany, 2002; Havermans and Jansen, 2003), and common neural circuits exists for extinction of fear and drug memories (Peters et al., 2009; Myers and Carlezon, 2010). Thus, extinction-reconsolidation manipulations can be potentially applied as a strategy to augment extinction retention in drug addiction and to restore control over drug cravings. Impairments in extinction have also been reported in a subset of schizophrenia patients who showed a general inability to retrieve safety signals (Holt et al., 2009). It is tempting to speculate that reducing fear memories with a reconsolidation-extinction approach could ameliorate some of the high anxiety and emotional dysregulation seen in schizophrenia.

Rodent models of stress-mediated depression demonstrate that traumatic stressors impair fear extinction and produce significant abnormalities in the morphology of mPFC and amygdala neurons (Holmes and Wellman, 2009; Roozendaal et al., 2009). Studies of major depression in humans observe abnormal neuronal morphology (Hercher et al., 2009), deficient activity (Koenigs and Grafman, 2009), and altered functional connectivity of mPFC (Frodl et al., 2010) correlated with the pathophysiology of depression and enhanced memory for negative emotions seen in this disorder (Hamilton and Gotlib, 2008). Although extinction has not been explicitly studied in depression (but see Jovanovic et al., 2010), these findings suggest that further characterization of the efficacy, strength, and limitations of novel extinction strategies could lead to new therapeutic approaches for the emotional processing deficits seen in depression and other psychiatric disorders.

\section{References}

Amano T, Unal CT, Paré D (2010) Synaptic correlates of fear extinction in the amygdala. Nat Neurosci 13:489-494.

Balmer TS, Carels VM, Frisch JL, Nick TA (2009) Modulation of perineuronal nets and parvalbumin with developmental song learning 1 . J Neurosci 29:12878-12885.

Berardi N, Lodovichi C, Caleo M, Pizzorusso T, Maffei L (1999) Role of neurotrophins in neural plasticity: what we learn from the visual cortex. Restor Neurol Neurosci 15:125-136.

Berardi N, Pizzorusso T, Ratto GM, Maffei L (2003) Molecular basis of plasticity in the visual cortex. Trends Neurosci 26:369-378.

Bissière S, Humeau Y, Lüthi A (2003) Dopamine gates LTP induction in lateral amygdala by suppressing feedforward inhibition 46. Nat Neurosci 6:587-592.

Bouton ME, Bolles RC (1979) Role of conditioned contextual stimuli in reinstatement of extinguished fear. J Exp Psychol Anim Behav Process 5:368-378.

Bruce SE, Yonkers KA, Otto MW, Eisen JL, Weisberg RB, Pagano M, Shea MT, Keller MB (2005) Influence of psychiatric comorbidity on recovery and recurrence in generalized anxiety disorder, social phobia, and panic disorder: a 12-year prospective study. Am J Psychiatry 162:1179-1187.

Brunet A, Orr SP, Tremblay J, Robertson K, Nader K, Pitman RK (2008) Effect of post-retrieval propranolol on psychophysiologic responding during subsequent script-driven traumatic imagery in post-traumatic stress disorder. J Psychiatr Res 42:503-506.

Chhatwal JP, Gutman AR, Maguschak KA, Bowser ME, Yang Y, Davis M, Ressler KJ (2009) Functional interactions between endocannabinoid and CCK neurotransmitter systems may be critical for extinction learning. Neuropsychopharmacology 34:509-521.

Conklin CA, Tiffany ST (2002) Applying extinction research and theory to cue-exposure addiction treatments. Addiction 97:155-167.

Dudai Y (2006) Reconsolidation: the advantage of being refocused. Curr Opin Neurobiol 16:174-178.

Ehrlich I, Humeau Y, Grenier F, Ciocchi S, Herry C, Lüthi A (2009) Amygdala inhibitory circuits and the control of fear memory. Neuron 62:757-771.

Falls WA, Miserendino MJ, Davis M (1992) Extinction of fear-potentiated startle: blockade by infusion of an NMDA antagonist into the amygdala. J Neurosci 12:854-863.

Forcato C, Burgos VL, Argibay PF, Molina VA, Pedreira ME, Maldonado H (2007) Reconsolidation of declarative memory in humans. Learn Mem 14:295-303.

Frodl T, Bokde AL, Scheuerecker J, Lisiecka D, Schoepf V, Hampel H, Möller HJ, Brückmann H, Wiesmann M, Meisenzahl E (2010) Functional connectivity bias of the orbitofrontal cortex in drug-free patients with major depression. Biol Psychiatry 67:161-167.

Ganasen KA, Ipser JC, Stein DJ (2010) Augmentation of cognitive behavioral therapy with pharmacotherapy. Psychiatr Clin North Am 33:687-699.

Gogolla N, Caroni P, Lüthi A, Herry C (2009) Perineuronal nets protect fear memories from erasure. Science 325:1258-1261.

Gonzalez-Lima F, Bruchey AK (2004) Extinction memory improvement by the metabolic enhancer methylene blue. Learn Mem 11:633-640.

Graham BM, Richardson R (2010) Fibroblast growth factor-2 enhances extinction and reduces renewal of conditioned fear. Neuropsychopharmacology 35:1348-1355.

Hamilton JP, Gotlib IH (2008) Neural substrates of increased memory sensitivity for negative stimuli in major depression. Biol Psychiatry 63:1155-1162.

Havermans RC, Jansen AT (2003) Increasing the efficacy of cue exposure treatment in preventing relapse of addictive behavior. Addict Behav 28:989-994.

Hensch TK (2005) Critical period plasticity in local cortical circuits. Nat Rev Neurosci 6:877-888.

Hercher C, Turecki G, Mechawar N (2009) Through the looking glass: examining neuroanatomical evidence for cellular alterations in major depression. J Psychiatr Res 43:947-961.

Herry C, Ferraguti F, Singewald N, Letzkus JJ, Ehrlich I, Lüthi A (2010) Neuronal circuits of fear extinction. Eur J Neurosci 31:599-612.

Holmes A, Wellman CL (2009) Stress-induced prefrontal reorganization and executive dysfunction in rodents. Neurosci Biobehav Rev 33:773-783.

Holt DJ, Lebron-Milad K, Milad MR, Rauch SL, Pitman RK, Orr SP, Cassidy BS, Walsh JP, Goff DC (2009) Extinction memory is impaired in schizophrenia. Biol Psychiatry 65:455-463.

Hupbach A, Gomez R, Hardt O, Nadel L (2007) Reconsolidation of episodic memories: a subtle reminder triggers integration of new information. Learn Mem 14:47-53.

Jovanovic T, Norrholm SD, Blanding NQ, Davis M, Duncan E, Bradley B, Ressler KJ (2010) Impaired fear inhibition is a biomarker of PTSD but not depression. Depress Anxiety 27:244-251.

Kim J, Lee S, Park K, Hong I, Song B, Son G, Park H, Kim WR, Park E, Choe HK, Kim H, Lee C, Sun W, Kim K, Shin KS, Choi S (2007) Amygdala depotentiation and fear extinction. Proc Natl Acad Sci USA 104:20955-20960.

Kim JH, Richardson R (2010a) Extinction in preweanling rats does not involve NMDA receptors. Neurobiol Learn Mem 94:176-182. 
Kim JH, Richardson R (2010b) New findings on extinction of conditioned fear early in development: theoretical and clinical implications. Biol Psychiatry 67:297-303.

Kim JH, Hamlin AS, Richardson R (2009) Fear extinction across development: the involvement of the medial prefrontal cortex as assessed by temporary inactivation and immunohistochemistry. J Neurosci 29:10802-10808.

Kindt M, Soeter M, Vervliet B (2009) Beyond extinction: erasing human fear responses and preventing the return of fear. Nat Neurosci $12: 256-258$

Koenigs M, Grafman J (2009) The functional neuroanatomy of depression: distinct roles for ventromedial and dorsolateral prefrontal cortex. Behav Brain Res 201:239-243.

Ledgerwood L, Richardson R, Cranney J (2005) D-cycloserine facilitates extinction of learned fear: effects on reacquisition and generalized extinction. Biol Psychiatry 57:841-847.

Lin CH, Lee CC, Gean PW (2003a) Involvement of a calcineurin cascade in amygdala depotentiation and quenching of fear memory. Mol Pharmacol 63:44-52.

Lin CH, Yeh SH, Lu HY, Gean PW (2003b) The similarities and diversities of signal pathways leading to consolidation of conditioning and consolidation of extinction of fear memory. J Neurosci 23:8310-8317.

Maren S, Chang CH (2006) Recent fear is resistant to extinction. Proc Natl Acad Sci U S A 103:18020-18025.

Milad MR, Rauch SL (2007) The role of the orbitofrontal cortex in anxiety disorders. Ann N Y Acad Sci 1121:546-561.

Misanin JR, Miller RR, Lewis DJ (1968) Retrograde amnesia produced by electroconvulsive shock after reactivation of a consolidated memory trace. Science 160:554-555.

Monfils MH, Cowansage KK, Klann E, LeDoux JE (2009) Extinctionreconsolidation boundaries: key to persistent attenuation of fear memories. Science 324:951-955.

Moriceau S, Wilson DA, Levine S, Sullivan RM (2006) Dual circuitry for odor-shock conditioning during infancy: corticosterone switches between fear and attraction via amygdala. J Neurosci 26:6737-6748.

Morris RW, Bouton ME (2007) The effect of yohimbine on the extinction of conditioned fear: a role for context. Behav Neurosci 121:501-514.

Myers KM, Carlezon WA Jr (2010) Extinction of drug- and withdrawalpaired cues in animal models: Relevance to the treatment of addiction. Neurosci Biobehav Rev. Advance online publication. Retrieved July 14, 2010. doi:10.1016/j.neubiorev.2010.01.011.

Myers KM, Davis M (2007) Mechanisms of fear extinction. Mol Psychiatry 12:120-150.

Myers KM, Ressler KJ, Davis M (2006) Different mechanisms of fear extinction dependent on length of time since fear acquisition. Learn Mem 13:216-223.

Nader K, Einarsson EO (2010) Memory reconsolidation: an update. Ann N Y Acad Sci 1191:27-41.

Nader K, Schafe GE, Le Doux JE (2000) Fear memories require protein synthesis in the amygdala for reconsolidation after retrieval. Nature 406:722-726.

Norrholm SD, Vervliet B, Jovanovic T, Boshoven W, Myers KM, Davis M, Rothbaum B, Duncan EJ (2008) Timing of extinction relative to acquisition: a parametric analysis of fear extinction in humans. Behav Neurosci 122:1016-1030
Nowicka D, Soulsby S, Skangiel-Kramska J, Glazewski S (2009) Parvalbumincontaining neurons, perineuronal nets and experience-dependent plasticity in murine barrel cortex 1. Eur J Neurosci 30: 2053-2063.

Ollendick TH, Ost LG, Reuterskiöld L, Costa N, Cederlund R, Sirbu C, Davis TE 3rd, Jarrett MA (2009) One-session treatment of specific phobias in youth: a randomized clinical trial in the United States and Sweden. J Consult Clin Psychol 77:504-516.

Pape HC, Paré D (2010) Plastic synaptic networks of the amygdala for the acquisition, expression, and extinction of conditioned fear. Physiol Rev 90:419-463.

Pavlov I (1927) Conditioned reflexes. London: Oxford UP.

Peters J, Kalivas PW, Quirk GJ (2009) Extinction circuits for fear and addiction overlap in prefrontal cortex. Learn Mem 16:279-288.

Peters J, Dieppa-Perea LM, Melendez LM, Quirk GJ (2010) Induction of fear extinction with hippocampal-infralimbic BDNF. Science 328:1288-1290.

Quirk GJ, Mueller D (2008) Neural mechanisms of extinction learning and retrieval. Neuropsychopharmacology 33:56-72.

Radulovic J, Tronson NC (2010) Molecular specificity of multiple hippocampal processes governing fear extinction. Rev Neurosci 21:1-17.

Rescorla RA, Heth CD (1975) Reinstatement of fear to an extinguished conditioned stimulus. J Exp Psychol Anim Behav Process 1:88-96.

Richardson R, Ledgerwood L, Cranney J (2004) Facilitation of fear extinction by D-cycloserine: theoretical and clinical implications. Learn Mem 11:510-516.

Roozendaal B, McEwen BS, Chattarji S (2009) Stress, memory and the amygdala. Nat Rev Neurosci 10:423-433.

Schiller D, Cain CK, Curley NG, Schwartz JS, Stern SA, Ledoux JE, Phelps EA (2008) Evidence for recovery of fear following immediate extinction in rats and humans. Learn Mem 15:394-402.

Schiller D, Monfils MH, Raio CM, Johnson DC, Ledoux JE, Phelps EA (2010) Preventing the return of fear in humans using reconsolidation update mechanisms. Nature 463:49-53.

Shaban H, Humeau Y, Herry C, Cassasus G, Shigemoto R, Ciocchi S, Barbieri S, van der Putten H, Kaupmann K, Bettler B, Lüthi A (2006) Generalization of amygdala LTP and conditioned fear in the absence of presynaptic inhibition. Nat Neurosci 9:1028-1035.

Soeter M, Kindt M (2010) Dissociating response systems: erasing fear from memory. Neurobiol Learn Mem 94:30-41.

Walker DL, Ressler KJ, Lu KT, Davis M (2002) Facilitation of conditioned fear extinction by systemic administration or intra-amygdala infusions of D-cycloserine as assessed with fear-potentiated startle in rats. J Neurosci 22:2343-2351.

Walker MP, Brakefield T, Hobson JA, Stickgold R (2003) Dissociable stages of human memory consolidation and reconsolidation. Nature 425:616-620.

Woods AM, Bouton ME (2006) D-cycloserine facilitates extinction but does not eliminate renewal of the conditioned emotional response. Behav Neurosci 120:1159-1162.

Woods AM, Bouton ME (2008) Immediate extinction causes a less durable loss of performance than delayed extinction following either fear or appetitive conditioning. Learn Mem 15:909-920.

Yap CS, Richardson R (2007) Extinction in the developing rat: an examination of renewal effects. Dev Psychobiol 49:565-575. 